\title{
Introduction to HICCS-52 Minitrack on Digital Workforce and Crowd Work
}

\author{
Xuefei (Nancy) Deng \\ California State University, \\ Dominguez Hills \\ ndeng@csudh.edu
}

\author{
Sara Moussaswi \\ Carnegie Mellon University \\ smoussaw@andrew.cmu.edu
}

\author{
Joseph D. Taylor \\ California State University, \\ Sacramento \\ joseph.taylor@csus.edu
}

\section{Introduction}

The emerging, complex phenomenon of crowd work and digital workforce have attracted increasing attention from both industry and academia, as evidenced by the recent calls for paper submissions to the special issue on "Optimizing the Digital Workforce" by MIS Quarterly Executive and the special issue of "Strategic Perspectives on Digital Work and Organizational Transformation” by Journal of Strategic Information Systems.

In organization research, work enrichment perspective premises that jobs should be enriched rather than simplified to enhance work quality. When a job is designed to embed certain job characteristics, workers who perform those jobs will be more likely to find the work meaningful, feel responsible for work outcomes, and have accurate feedback regarding their work outcomes, all of which will foster their intrinsic work motivation [1].

Advancements in information technologies have transformed how organization work is designed, performed and managed. Instead of the established archetype of 9-5 office work, many organizations adopt mobile or remote work, and tap into the flexible, on-demand workforce on dedicated platforms such as Amazon Mechanical Turk (MTurk), Uber, and TaskRabbit. Crowd work is such a new form of work where organizations can push small human computing tasks on third party online platforms such as MTurk on a mass scale and benefit from a flexible, on-demand virtual workforce. This emerging crowd work environment is shaped by six essential characteristics, including on-demand virtual labor, open access to work, Internet access to join the crowd, human tasks, modular technical architecture, and three stakeholders of crowdsourcer, crowdsourcee, and crowdsourcing intermediary [2].

Made possible by the material properties of digital technologies, the enriching properties of crowd work demonstrate the need to expand on traditional work design theory by integrating motivational, social, and work context characteristics. While the digital workforce brings new, important competencies to the workplace, it may also develop new identity and new way of collaborating [3]. One of the compelling aspects of the "Digital Workforce and Crowdwork" is unique benefits and opportunities that it provides to both workers and firms engaged in digital activities [4]. For example, workers on MTurk are driven not only by their needs of existence (e.g. workers' rights, source of income) but also by the benefits of relatedness (e.g. connectedness to others, belongingness and impact on society), and opportunity for growth (e.g. skill development) [5]. Moreover, the digitalization of work is transforming not just organizations and industries, but potentially the whole labor market [6], calling for updating and developing public policies governing the emerging, global digital work environments and managing the digital workforce.

\section{Scope}

The minitrack focuses on all aspects of digital work and digital workforce. Research of this minitrack lies at the intersections of multiple disciplines, namely Information Technology, Organization Science, Human Resource Management, and Behavioral Science. This minitrack publishes both theoretical and empirical studies addressing organizational, managerial, technical, and behavioral perspectives on digital workforce and crowd work.

Topics and issues presented in this minitrack include, but not limited to:

- Crowd work and work design

- Digital workforce and human resource management

- Digital workforce and motivations

- Digital competence and professional development

- Ethical concerns of digital workforce

- Ethics in the digital workplace 
- Future of work and workplace

- New forms of IT-enabled work (e.g., elancing)

- Psychological aspects of digital workplace (e.g., Technostress)

- Voicing behaviors of digital workforce

- Work practices in hyper-digital environment

\section{Summary of Articles}

This mini-track presents three paper in HICCS52. We introduce them briefly below.

First, digitization has transformed organizational workplaces. In their research, Durward, Simmert, Peters, Blohm, and Leimeister [7] focus on a new form of digital work, internal crowd work, and identify structural antecedents that affect psychological empowerment of internal crowd workers. Their paper, titled "How to Empower the Workforce - Analyzing Internal Crowd Work as a Neo-Socio-Technical System”, analyzes internal crowd work as neo-socio-technical system out of an employee's perspective, and contributes to the psychological factors influencing employees adapting to this new work form of crowd work.

Second, digitization has given rise to a shared accommodation economy. In their paper, titled "Spatial and Socioeconomic Analysis of Host Participation in the Shared Accommodation Economy - Airbnb in New York City," Sarkar, Koohikamali, and Pick [8] develop a theoretical conceptual model of host participation in the shared accommodation economy and its socioeconomic antecedents, and empirically validate it by using a large sample of New York City (NYC) neighborhoods. The OLS regression analysis of Airbnb listings in NYC over a three-year span from 2015 to 2017 reveals interesting spatial patterns of Airbnb property densities: the host participation in NYC Airbnb market was found declining with higher proportion of ethnic minorities but increasing with a higher proportion of digitally competent employees. The findings provide useful implications to understand motivations of the digital workforce.

Third, in today's digital economy, millennials seek flexibility and task significance, while also stressing their individual careers over joining a corporation. In their paper, titled "Self-Employment as a Career Path for Millennials in the Digital Economy,” Figueroa-Armijos and da Motta Veiga [9] propose that self-employment can provide such a career path for millennials, and examine whether and how individual (i.e. job satisfaction and personality) and family (parental monitoring) variables influence the decision to pursue self-employment for millennials over a three-year period. The analysis of a large national U.S. database (NLSY97) shows that self-employment offers a viable short-term career path or a sustainable career path among millennials under different conditions. The study suggests that millennials' expectations and attitudes towards today's digital economy and workplace - meaningful jobs, supportive and flexible environment, work-life balance, and high pay - align synchronously with the characteristics of sustainable career frameworks.

\section{Reference}

[1] Hackman, J. R., and G. R. Oldham. "Motivation through the design of work: Test of a theory," Organizational Behavior and Human Performance, vol. 16, no. 2, 1979, pp.250-279.

[2] Deng, X., and K. D. Joshi. "Why Individuals Participate in Micro-task Crowdsourcing Work Environment: Revealing Crowdworkers' Perceptions," Journal of the Association for Information Systems, vol. 17, no. 10, 2016, pp.711-736.

[3] Colbert, A., N. Yee, and G. George. "The digital workforce and the workplace of the future," Academy of Management Journal, vol. 59, no. 3, 2016, pp.731739.

[4] Taylor, J., and K. D. Joshi. "Joining the Crowd: The Career Anchors of Information Technology Workers Participating in Crowdsourcing," Information Systems Journal, 2018. https://doi.org/10.1111/isj.12225

[5] Moussawi, S., and M. Koufaris. "Working on LowPaid Micro-Task Crowdsourcing Platforms: An Existence, Relatedness and Growth View," Paper presented at the International Conference on Information Systems, 2015, Fort Worth, Texas.

[6] Deng, X, K. D. Joshi, and R. D. Galliers. "The Duality of Empowerment and Marginalization in Microtask Crowdsourcing: Giving Voice to the Less Powerful through Value Sensitive Design", MIS Quarterly, vol. 40, no. 2, 2016, pp.279-302.

[7] Durward, D., B. Simmert, C. Peters, I. Blohm, and J. M. Leimeister. "How to Empower the Workforce Analyzing Internal Crowd Work as a Neo-SocioTechnical System", in Proceedings of the 52nd Hawaii International Conference on Systems Science (HICSS -52), January 8 -11, 2019, Maui, Hawaii.

[8] Sarkar, A., M. Koohikamali, and J. B. Pick. "Spatial and Socioeconomic Analysis of Host Participation in the Shared Accommodation Economy - Airbnb in New York City," in Proceedings of the 52nd Hawaii International Conference on Systems Science (HICSS 52), January 8 -11, 2019, Maui, Hawaii.

[9] Figueroa-Armijos, M., and S. P., da Motta Veiga. "Self-Employment as a Career Path for Millennials in the Digital Economy," in Proceedings of the 52nd Hawaii International Conference on Systems Science (HICSS -52), January 8 -11, 2019, Maui, Hawaii. 